Case Report

\title{
Goiter in a Patient with Pulmonary Arterial Hypertension Treated with Epoprostenol
}

\author{
Shaadi Abughazaleh (D) and Zeenat Safdar \\ Department of Pulmonary-Critical Care Medicine, Houston Methodist Hospital, Weill Cornell College of Medicine, \\ Houston, TX, USA \\ Correspondence should be addressed to Zeenat Safdar; zsafdar@houstonmethodist.org
}

Received 22 September 2019; Accepted 25 November 2019; Published 23 January 2020

Academic Editor: Chih-Yen Tu

Copyright (C) 2020 Shaadi Abughazaleh and Zeenat Safdar. This is an open access article distributed under the Creative Commons Attribution License, which permits unrestricted use, distribution, and reproduction in any medium, provided the original work is properly cited.

\begin{abstract}
A 35-year-old female with pulmonary arterial hypertension (PAH) who presented with complaints of progressively worsening dysphagia, facial swelling, and shortness of breath, was found to have a large goiter. In patients treated with epoprostenol for long periods of time, thyroid disease is common. Most cases of thyroid disease describe thyrotoxicosis and hyperthyroid statues, but our case was a patient on long term IV epoprostenol presenting with a superior vena cava-syndrome (SVC) like appearance and airway compromise found to have a goiter incidentally during workup.
\end{abstract}

\section{Introduction}

Pulmonary arterial hypertension is a rare disease which occurs in 5-50 per one million adults [1-3]. This life-threatening disease occurs $2-4 \mathrm{x}$ more commonly in females compared to men [3, 4]. Although with new treatment modalities PAH-related hospitalizations and death are decreasing during the last decade [5, 6], many of PAH medications have significant side effects. A number of studies have documented that in patients diagnosed with hyperthyroidism, $35-47 \%$ were also found to have PAH. Whereas, studies have shown that anywhere between $22.5 \%$ and $49 \%$ of PAH patients have hyperthyroidism [7], although a clear causality has not yet been described. We present a case of PAH patients on long-term intravenous epoprostenol infusion who presented with an enlarging goiter with compression symptoms.

\section{Case}

A 35-year-old African-American female was diagnosed with PAH in 2010, five-months after the birth of her $3^{\text {rd }}$ child. She started noticing progressive shortness of breath including an episode of syncope while walking into a shower. She denied any drug abuse or anorexigen use. She saw a number of doctors including neurologist, cardiologist and pulmonologist and remembers receiving "every test you can think of" before she was referred to pulmonary hypertension specialist. Her echocardiogram (ECHO) showed elevated right ventricular pressure (Table 1). She underwent full pulmonary hypertension work up including a right heart catheterization (RHC) that demonstrated a mean pulmonary artery pressure of $52 \mathrm{mmHg}$ (Table 2). Computed tomography of chest showed an enlarged pulmonary trunk measuring $3.7 \mathrm{~cm}$ and borderline cardiomegaly but no interstitial changes. The ventilationperfusion scan showed a low probability of pulmonary embolism. She was started on sildenafil and ambrisentan and inhaled treprostinil was subsequently added with only marginal improvement of symptoms. Therefore, she was rapidly transitioned to intravenous epoprostenol. With this, she noticed a marked improvement in her shortness of breath and functionality. In 2015, she was evaluated by ophthalmology for headaches due to concern for nonarteritic anterior ischemic optic neuropathy (NAION), and sildenafil was discontinued. In 2018, she underwent a repeat RHC for worsening shortness of breath that showed mean PAP of $60 \mathrm{mmHg}$, right atrial pressure of $5 \mathrm{mmHg}$, cardiac output of 2.78 liters per minute and MVO2 of $59 \%$. She started complaining of shortness of breath, neck swelling and pain, dyspnea, dysphagia and occasional dysphonia. Physical exam showed evidence of an 
TABLE 1: Non-invasive hemodynamics.

\begin{tabular}{|c|c|c|c|c|c|}
\hline Date & $\mathrm{RAP}(\mathrm{mmHg})$ & RVSP (mmHg) & $\mathrm{CI}\left(\mathrm{L} / \mathrm{min} / \mathrm{m}^{2}\right)$ & HR (bpm) & Mean BP $(\mathrm{mmHg})$ \\
\hline $11 / 2 / 10$ & 15 & 87 & 1.29 & 52 & 104 \\
\hline $2 / 16 / 11$ & 15 & 80 & 1.61 & 73 & 110.5 \\
\hline $3 / 6 / 12$ & 10 & 105 & 1.36 & 91 & 90 \\
\hline 4/8/13 (pre-flolan) & 10 & 100 & 2.4 & 78 & 86 \\
\hline 7/23/13 (post-flolan) & 15 & 133 & 2.1 & 95 & 88 \\
\hline $6 / 6 / 14$ & 5 & 81 & 2.1 & 89 & 82.5 \\
\hline $3 / 4 / 15$ & 5 & 110 & 2.35 & - & - \\
\hline $10 / 6 / 15$ & 10 & 91 & 1.7 & - & - \\
\hline $8 / 2 / 18$ (pre-surgery) & 5 & 75 & 2.0 & 84 & 66.5 \\
\hline $8 / 5 / 18$ (post-surgery) & 5 & 70 & Not reported & 80 & 74.5 \\
\hline $11 / 14 / 18$ & 10 & 100 & 3.6 & 91 & 81.5 \\
\hline $2 / 20 / 19$ & 5 & 90 & 4.1 & 92 & 72 \\
\hline
\end{tabular}

TABLE 2: Invasive hemodynamics.

\begin{tabular}{lccccc}
\hline Date & RAP $(\mathrm{mmHg})$ & Mean PA $(\mathrm{mmHg})$ & PAWP $(\mathrm{mmHg})$ & $\begin{array}{c}\text { Cardiac index }(\mathrm{L} / \mathrm{min} / \\
\left.\mathrm{m}^{2}\right)\end{array}$ & \multicolumn{2}{c}{ SVO2 $(\%)$} \\
\hline $11 / 15 / 10$ & 8 & 52 & 11 & 1.98 & 64.5 \\
$7 / 18 / 12$ & $8-12$ & 60 & $8-12$ & 1.98 & 59.4 \\
$2 / 1 / 18$ (Pre-surgery) & 5 & 60 & 8 & 1.86 & 59.3 \\
\hline
\end{tabular}

TABLE 3: Thyroid studies.

\begin{tabular}{lc}
\hline T4 & $1.4 \mu \mathrm{g} / \mathrm{dL}(4.5-11.7 \mu \mathrm{g} / \mathrm{dL})$ \\
Free T4 & $1.0 \mathrm{mg} / \mathrm{dL}(0.9-1.7 \mathrm{ng} / \mathrm{dL})$ \\
TSH & $0.34 \mu \mathrm{IU} / \mathrm{mL}(0.27-4.20 \mu \mathrm{IU} / \mathrm{mL})$ \\
Thyroglobulin antibody & Undetectable \\
Thyroglobulin serum & $147.6 \mathrm{ng} / \mathrm{mL}(1.3-31.8 \mathrm{ng} / \mathrm{mL})$ \\
Thyroperoxidase antibody & $70.4 \mathrm{IU} / \mathrm{mL}(0.0-9.0 \mathrm{IU} / \mathrm{mL})$ \\
\hline
\end{tabular}

enlarging neck mass resulting in dyspnea and anxiety. There was progressive worsening in her shortness of breath, which was not attributable to $\mathrm{PAH}$, so endocrinology was consulted. Thyroid studies showed $\mathrm{T} 4=1.4 \mathrm{ng} / \mathrm{dL} \quad(0.9-1.7 \mathrm{ng} / \mathrm{dL})$, $\mathrm{TSH}=0.34 \mu \mathrm{IU} / \mathrm{mL} \quad(0.27-4.20 \mu \mathrm{IU} / \mathrm{mL})$, undetectable thyroglobulin antibody, elevated thyroglobulin serum at $147.6 \mathrm{ng} / \mathrm{mL}(1.3-31.8 \mathrm{ng} / \mathrm{mL})$ and thyroperoxidase antibody at $70.4 \mathrm{IU} / \mathrm{mL}(0.0-9.0 \mathrm{IU} / \mathrm{mL}$ ) (seen in Table 3). Further lab workup showed stable electrolytes and baseline renal function.

CT chest (Figure 1) and neck (Figure 2) were done for initial evaluation for her in the setting of dyspnea, neck swelling and pain which showed thyromegaly with $1.6 \mathrm{~cm}$ isthmus nodule and $2 \mathrm{~cm}$ left thyroid (seen in Figure 2).

Subsequent fine needle aspiration of both nodules showed no evidence of malignancy and only findings of benign follicular consistent with an adenomatous nodule. Radioactive iodine uptake test showed absence of thyroid uptake, thyroid stimulating immunoglobulin was negative, and there was no evidence of Graves' disease or hyper-functioning thyroid. In the setting of laboratory euthyroidism and a goiter with the characteristics mentioned above, she was diagnosed with silent (painless) thyroiditis. With this diagnosis, radioactive iodine ablation was not deemed necessary as she was in the euthyroid

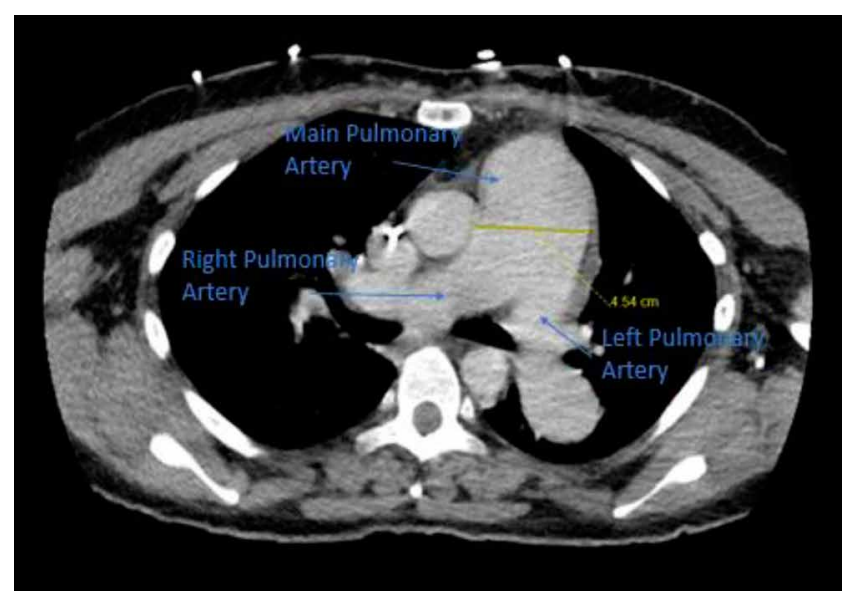

FIGURE 1: CT chest with contrast showing enlarged pulmonary artery measuring $4.5 \mathrm{~cm}$.

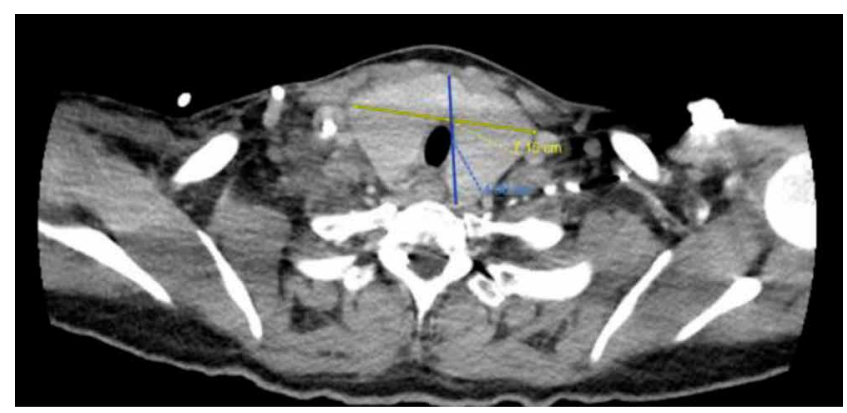

FIGURE 2: CT chest with contrast showing enlarged thyroid gland approximately $7 \times 5 \mathrm{~cm}$ in size.

state. However, patient continued to have progressively worsening compressive symptoms from her enlarging goiter. After 


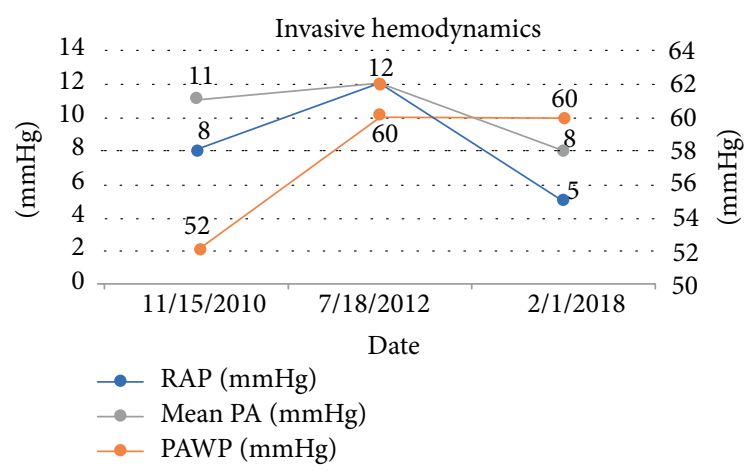

FIGURE 3: Figure representing changes in RAP, Mean PAP, and PAWP at time points leading up to her procedure.

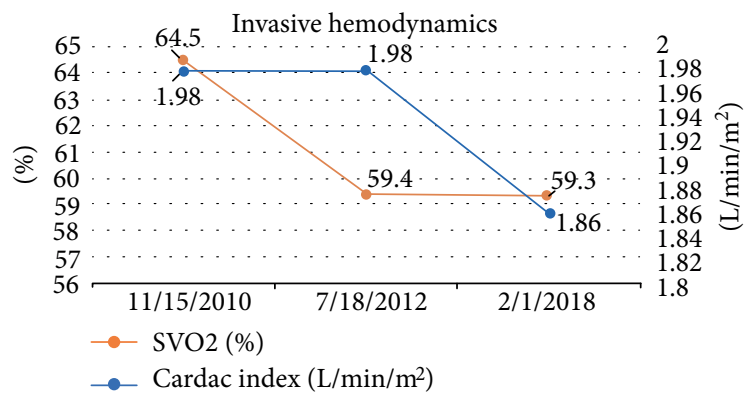

FIGURE 4: Figure representing changes in SVO2 and cardiac index at time points leading up to her procedure.

discussion with Otolaryngology and Endocrinology, it was recommended that she have her goiter removed.

She was admitted for thyroidectomy and her PAH meds were optimized [riociguat was added and rapidly up-titrated to $2.5 \mathrm{mg}$ TID; epoprostenol dose at $48 \mathrm{ng} / \mathrm{kg} / \mathrm{min}$ and ambrisentan $10 \mathrm{mg}$ daily were continued]. Multidisciplinary meetings were held with cardiovascular anesthesia, ICU team and surgeons regarding the importance of continuing epoprostenol during this procedure along with recommendations to use inhaled agents, avoiding propofol during induction. She successfully underwent thyroidectomy without any complications and with full post-operative recovery. Following her surgery, ECHO showed estimated RVSP of $65-70 \mathrm{mmHg}$, severely enlarged right ventricle with severely depressed systolic function and right atrial pressure of $5 \mathrm{mmHg}$. Patient was continued on epoprostenol $48 \mathrm{ng} / \mathrm{kg} / \mathrm{min}$, ambrisentan $10 \mathrm{mg}$ daily and riociguat $2.5 \mathrm{mg}$ three times per day with outpatient follow-up. At 6 month follow-up, patient self-reports WHO Class III functional status. Patient's RAP, Mean PAP, and PAWP over time are shown in Figure 3. Patient's SVO2 and Cardiac Index over time are shown in Figure 4. She continues to be on stable doses of epoprostenol and riociguat with plans for future RHC and gradual increase in epoprostenol as tolerated.

\section{Discussion}

This patient was treated with intravenous epoprostenol who presented with an enlarging goiter. Seronegative thyrotoxicosis, diffuse goiters, and homogenous uptake on thyroid scintigraphy in patients on long term epoprostenol therapy has been reported by Chadha et al. [8]. It was found that $6.7 \%$ of patients with PAH treated with PGI2 had thyroidstimulating immunoglobulin-negative thyrotoxicosis in the absence of other factors that could be contributing to their hyperthyroid state. This number was significantly greater than expected rates in the general population [8].

It is important to distinguish patients treated with IV Epoprostenol from patients who present with $\mathrm{PAH}$ and thyroid disease, two diseases that have known associations. It has been proposed that the direct influence of thyroid hormone on the pulmonary vasculature can cause increased pressures. In multiple case reports, patients with Graves' disease saw decreases in, and at times, normalization of PASP after the treatment of thyroid disease [7]. In a study comparing epoprostenol and endothelin receptor antagonists in the development of thyrotoxicosis in patients with PAH, it was found that when compared to patients on combination therapy, patients being treated with only epoprostenol had significantly higher odds of thyrotoxicosis [9]. This leads practitioners to believe that thyrotoxicosis may be promoted by epoprostenol and inhibited by endothelin receptor antagonists which are often used in the treatment of PAH.

In this case, the patient had been treated with IV epoprostenol for more than 6 years and was found to have a goiter causing airway compression and an SVC-syndrome-like manifestation with facial swelling, shortness of breath and difficulty swallowing foods. Prior thyroid studies and imaging completed prior to initiation of epoprostenol were unremarkable. Upon further investigation, patient was found to be in a euthyroid state which was unique when compared to the hyperthyroid state many of the previous case reports had described. This case's purpose is to make practitioners who treat PAH with epoprostenol aware of not only the association with thyrotoxicosis and hyperthyroid states but also aware that goiters presenting with an SVC-syndrome like appearance and airway compression may occur with long-term use of epoprostenol.

\section{Conflicts of Interest}

The authors declare that they have no conflicts of interest.

\section{References}

[1] M. Humbert, O. Sitbon, A. Chaouat et al., "Pulmonary arterial hypertension in France: results from a national registry," American Journal of Respiratory and Critical Care Medicine, vol. 173, no. 9, pp. 1023-1030, 2006.

[2] Y. Ling, M. K. Johnson, D. G. Kiely et al., "Changing demographics, epidemiology, and survival of incident pulmonary arterial hypertension: results from the pulmonary hypertension registry of the United Kingdom and Ireland," American Journal of Respiratory and Critical Care Medicine, vol. 186, no. 8, pp. 790-796, 2012.

[3] M. D. McGoon, R. L. Benza, P. Escribano-Subias et al., "Pulmonary arterial hypertension: epidemiology and registries," Journal of the American College of Cardiology, vol. 62, 25, pp. 51-59, 2013. 
[4] A. E. Frost, D. B. Badesch, R. J. Barst et al., "The changing picture of patients with pulmonary arterial hypertension in the United States: how REVEAL differs from historic and nonUS contemporary registries," Chest, vol. 139, no. 1, pp. 128-137, 2011.

[5] V. Anand, S. S. Roy, S. L. Archer et al., "Trends and outcomes of pulmonary arterial hypertension-related hospitalizations in the United States: analysis of the nationwide inpatient sample database from 2001 through 2012," JAMA Cardiology, vol. 1, no. 9, pp. 1021-1029, 2016.

[6] P. D. Stein, F. Matta, and P. G. Hughes, "Scope of problem of pulmonary arterial hypertension," The American Journal of Medicine, vol. 128, no. 8, pp. 844-851, 2015.

[7] D. R. Silva, M. B. Gazzana, Â. B. John et al., "Pulmonary arterial hypertension and thyroid disease," Jornal Brasileiro de Pneumologia, vol. 35, no. 2, pp. 179-185, 2009.

[8] C. Chadha, M. Pritzker, and C. Mariash, "Effect of Epoprostenol on the thyroid gland: enlargement and secretion of thyroid hormone," Endocrine Practice, vol. 15, no. 2, pp. 116-121, 2009.

[9] M. Satoh, K. Aso, T. Nakayama, and T. Saji, "Effect of treatment with epoprostenol and endothelin receptor antagonists on the development of thyrotoxicosis in patients with pulmonary arterial hypertension," Endocrine Journal, vol. 64, no. 12, pp. 1173-1180, 2017. 